\title{
Early-life risk factors for chronic nonrespiratory diseases
}

\author{
Archana Chacko ${ }^{1}$ David O. Carpenter ${ }^{2}$, Leonie Callaway ${ }^{3}$ and Peter D. Sly ${ }^{1}$
}

Number 5 in the series "Multimorbidity and the lung"

Edited by L.M. Fabbri and J.M. Drazen

\begin{abstract}
Affiliations:
'World Health Organization Collaborating Centre for Children's Health and Environment, Queensland Children's Medical Research Institute, The University of Queensland, Brisbane, Australia.

${ }^{2}$ World Health Organization Collaborating Centre in Environmental Health, Institute for Health and the Environment, University at Albany, Albany, NY, USA.

${ }^{3}$ School of Medicine, The University of Queensland, Brisbane, Australia.
\end{abstract}

\section{Correspondence:}

Peter D. Sly, Queensland Children's Medical Research Institute, Level 4, Foundation Building, Royal Children's Hospital, Herston Rd, Herston, Qld 4029, Australia.

E-mail: peterdichr.uwa.edu.au

ABSTRACT We have witnessed a change in disease patterns contributing to the global burden of disease, with a shift from early childhood deaths due to the classic infectious communicable diseases to years lived with disability from chronic noncommunicable diseases. In both developing and developed countries, the years lived with disability attributable to chronic disease have increased: cardiovascular diseases by $17.7 \%$; chronic respiratory disease by $8.5 \%$; neurological conditions by $12.2 \%$; diabetes by $30.0 \%$; and mental and behavioural disorders by $5.0 \%$ over the past 20 years. Recognition of the contribution made by adverse environmental exposures in early life to noncommunicable diseases in later life is increasing. These earlylife exposures appear to contribute to both chronic respiratory and chronic nonrespiratory diseases. In this State of the Art article, we aim to examine early-life environmental exposures that have an epidemiological association with chronic nonrespiratory diseases, such as obesity and type II diabetes, cardiovascular disease, and neurocognitive and behavioural problems. We will highlight the potential overlap in environmental risks with respiratory diseases, and point out knowledge gaps and research opportunities.

@ERSpublications

Respiratory diseases are linked to obesity/diabetes/metabolic syndrome, CVD and neurocognitive/behavioural disorders http://ow.ly/CGbea

\footnotetext{
Received: April 152014 | Accepted after revision: Oct 022014 | First published online: Nov 132014

Previous articles in this series: No. 1: Faner R, Cruz T, López-Giraldo A, et al. Network medicine, multimorbidity and the lung in the elderly. Eur Respir J 2014; 44: 775-788. No. 2: Divo MJ, Martinez CH, Mannino DM. Ageing and the epidemiology of multimorbidity. Eur Respir J 2014; 44: 1055-1068. No. 3: MacNee W, Rabinovich RA, Choudhury G. Ageing and the border between health and disease. Eur Respir J 2014; 44: 1332-1352. No. 4: Carraro S, Scheltema N, Bont L, et al. Early-life origins of chronic respiratory diseases: understanding and promoting healthy ageing. Eur Respir J 2014; 44: 1682-1696.
}

Conflict of interest: None declared.

Copyright OERS 2015 


\section{Introduction}

Publication of the 2010 Global Burden of Disease estimates has shown a marked shift away from communicable towards noncommunicable diseases (NCDs) over the past 20 years [1], with an associated increase in both morbidity and mortality from these conditions. Early childhood deaths have declined and years lived with disability have increased [1]. Premature deaths do still occur, especially in low-income developing countries. Indoor air pollution, associated with cooking and heating with solid fuels (i.e. wood, crop residue, charcoal, coal and dung) in open fires, unflued stoves or poorly maintained and leaky stoves, is a major global problem affecting an estimated 3 billion people and causing 4.3 million premature deaths annually [2]. Among these deaths: $12 \%$ are from pneumonia, many of which are in children; $34 \%$ from stroke; $26 \%$ from ischaemic heart disease; $22 \%$ from chronic obstructive pulmonary disease (COPD); and $6 \%$ from lung cancer.

In both developing and developed countries, the years lived with disability attributable to chronic disease have increased: cardiovascular diseases (CVDs) by $17.7 \%$; chronic respiratory disease by $8.5 \%$; neurological conditions by $12.2 \%$; diabetes by $30.0 \%$; and mental and behavioural disorders by $5.0 \%$ over the past two decades [3]. These estimates and assessments of the hazards posed by underlying risk factors are based on conservative methodology that requires a very high level of proof before a risk factor can be included [4]. Table 1 shows the changes in risk factors recognised over the past 20 years. While several of the top risks have a clear environmental link, the present approach creates a structural bias by excluding newly recognised and emerging risk factors that have not yet achieved the full weight of evidence required for inclusion in the Global Burden of Disease estimates [6]. Adverse environmental exposures in early life are among the risk factors systematically excluded from consideration in the current methodology. Yet understanding is increasing that many chronic NCDs are initiated by early-life exposures to toxic chemicals together with nutritional imbalances and psychosocial stress [7].

The fetal and developmental origins of adult disease [8] currently generate much interest. Exposure to toxic or endocrine-disrupting chemicals in early life can influence metabolism to alter brain growth [9] or promote obesity [10-12], and play a substantial role in initiation and/or progression of diseases [13] including: respiratory diseases such as asthma, COPD and lung cancer; neurobehavioural disorders, including attention deficit hyperactivity disorder [14] and autism spectrum disorders; depression and other mental disorders; and obesity and type II diabetes [15]. While the mechanisms involved are not know with certainty, individual genetic susceptibility, gene-by-environment interactions and epigenetic mechanisms are likely to be involved [16]. An increasing body of evidence from animal studies suggests that environmental exposures increase disease susceptibility via epigenetic mechanisms [17]. Environmental toxicants have the potential to alter gene expression and modify disease susceptibility through induction of methylation of $\mathrm{CpG}$ dinucleotide sequences in promoter regions regulating common genes, in transposable elements adjacent to genes with metastable epialleles, and in regulatory elements of imprintable genes [17]. Solid data from human studies have been lacking but with the rapid advances in technology for assessing the "methylome" and "epigenome", this is an area of active current research.

TABLE 1 Top 10 risk factors contributing to the global burden of disease and how they have changed over the past 20 years

\begin{tabular}{|c|c|c|c|}
\hline \multirow[t]{2}{*}{ Rank } & \multirow{2}{*}{$\frac{1990}{\text { Risk factor }}$} & \multicolumn{2}{|c|}{2010} \\
\hline & & Risk factor & Change $^{\#} \%(95 \%$ UI) \\
\hline 1 & Childhood underweight & High blood pressure & $27(19-34)$ \\
\hline 2 & Household air pollution" & Smoking $^{+}$ & $3(-5-11)$ \\
\hline 3 & Smoking $^{+}$ & Alcohol use & $28(17-39)$ \\
\hline 4 & High blood pressure & Household air pollution" & $-37(-44--29)$ \\
\hline 5 & Suboptimal breast feeding & Low fruit consumption & $29(25-34)$ \\
\hline 6 & Alcohol use & High body mass index & $82(71-95)$ \\
\hline 7 & Ambient PM pollution & High fasting blood glucose & $58(43-73)$ \\
\hline 8 & Low fruit consumption & Childhood underweight & $-61(-66--55)$ \\
\hline 9 & High fasting blood glucose & Ambient PM pollution & $-7(-13--1)$ \\
\hline 10 & High body mass index & Physical inactivity & \\
\hline
\end{tabular}

UI: uncertainty interval; PM: particulate matter. ${ }^{\#}$ : in contribution to global burden of disease for the 2010 risk factor over the past 20 years; ${ }^{\text {I }}$ : predominantly due to burning solid or biomass fuel; ${ }^{+}$: excluding second-hand smoke. Data from [5]. 
Several factors contribute to the lack of recognition of early-life exposure to environmental toxicants as risk factors for NCDs. The contribution made by early-life environmental exposures to NCDs has only recently been recognised. Given the relatively long time between low-dose exposures in early life and disease expression many years later, there is a natural barrier in obtaining the appropriate data to establish this relationship. This can be solved either by very long-term studies or by shorter studies that demonstrate environmental contribution to recognised risk factors for NCDs; for example, low lung function is a recognised risk factor for COPD. Thus, studies linking environmental exposures during fetal development or infancy to low lung function at birth or in early childhood provide evidence for early-life contributions to COPD. Similarly, studies demonstrating early-life environmental exposures resulting in rapid weight gain and increased adiposity in infancy, both known risk factors for subsequent obesity, will help to bridge the evidence gap.

Another problem is that most, if not all of the population, are likely to be exposed to the environmental toxicants suspected as risk factors for NCDs. For example, a recent summary of human biomonitoring studies concluded that the exposure to bisphenol A (BPA), a synthetic compound with oestrogen-like activity that is used in the construction of polycarbonate plastics widely used in food and beverage containers, was ubiquitous [18]. Thus, traditional epidemiology methods that rely on comparing exposed with unexposed populations are not suitable for examining early-life exposure to BPA as a risk factor for NCDs in later life. Finally, as is becoming increasingly clear, age- and species-dependent susceptibility and metabolism confound translation of results of animal studies to humans or from studies in adults to infants. The consequence is that environmental exposures have not been accorded due consideration in public health planning and resource allocation [6].

In this State of the Art article, we aim to examine the evidence that early-life environmental exposures have adverse impacts on chronic nonrespiratory diseases, especially obesity and type II diabetes, CVD, and neurocognitive and behavioural problems. We will highlight links to chronic respiratory disease and potential common early-life exposures and risk factors, and point out knowledge gaps and research opportunities. While a full discussion of early-life exposures and risk factors for chronic respiratory disease is beyond the scope of this article and covered elsewhere in this series [19], a brief summary is warranted of exposures and risk factors that are common between respiratory and nonrespiratory disease. These factors are summarised in table 2 .

\section{Obesity and type II diabetes}

There is a growing body of evidence that shows that environmental chemical exposures increase the risk of development of obesity and type II diabetes [20]. The strongest associations are with persistent lipophilic pollutants. However, one reason why these associations have not received wide-spread acceptance is that, as lipophilic chemicals, they are stored in fat and obese people have a higher fat mass. However, the most convincing data come from a re-presentation of data from the US National Health and Nutrition

TABLE 2 Links between chronic respiratory and nonrespiratory diseases through common early-life exposures and risk factors

\begin{tabular}{|c|c|c|c|c|}
\hline Respiratory risk factor & Obesity & $\begin{array}{c}\text { Type II diabetes/ } \\
\text { metabolic syndrome }\end{array}$ & $\begin{array}{l}\text { Cardiovascular } \\
\text { disease }\end{array}$ & $\begin{array}{c}\text { Neurocognitive and } \\
\text { behavioural disorders }\end{array}$ \\
\hline \multicolumn{5}{|l|}{ Prenatal } \\
\hline Maternal smoking & Asthma, COPD? & Asthma, COPD & Asthma, COPD & Asthma, COPD \\
\hline Maternal stress & No link & Asthma & Not studied & Asthma \\
\hline Maternal undernutrition & Asthma, COPD & Asthma, COPD & Asthma, COPD & Asthma \\
\hline Breast feeding, early weaning, diet & Asthma & Via obesity ${ }^{\S}$ & No link & Asthma \\
\hline Low birth weight and catch-up growth & Asthma & Via obesity & Asthma, COPD & Asthma \\
\hline Environmental tobacco smoke & Asthma, COPD & Asthma, COPD & Asthma, COPD & Asthma \\
\hline Low socioeconomic status & Asthma, COPD & Asthma, COPD & Asthma, COPD & Asthma, COPD \\
\hline GIT microbiota dysbiosis & Asthma & Asthma & No link & No link \\
\hline Air pollution & Asthma, COPD & Asthma, COPD & Asthma, COPD & No link \\
\hline
\end{tabular}


Examination Survey, which originally showed a strong dose-response relationship between serum concentrations of persistent organic pollutants and diabetes [21]. In re-presenting the data, PORTA and LEE [22] clearly demonstrated an influence of the serum concentrations of persistent organic pollutants on diabetes, independent of body mass index (BMI). They showed that people with the lowest chemical concentrations had almost zero risk of diabetes regardless of their BMI (fig. 1). In addition, the risk of diabetes climbed progressively with increasing pollutant levels, even in normal-weight individuals (BMI $<25 \mathrm{~kg} \cdot \mathrm{m}^{-2}$ ) [22]. There is also increasing evidence suggesting that BPA may be diabetogenic [23, 24]. Urine levels of BPA have been positively correlated with CVD and type II diabetes [25]. In animal studies, BPA exposure has been shown to cause the metabolic syndrome, including insulin resistance [23, 26-28].

While the associations between exposure to a variety of environmental chemicals and obesity and diabetes have been seen across the life span, recent studies implicate exposure before birth as an important factor that increases the risk of obesity later in life. The impact of prenatal exposure increasing the risk of obesity has been demonstrated in humans for maternal tobacco smoke [29]; dichlorodiphenyldichloroethylene (DDE), the metabolite of dichlorodiphenyltrichloroethane (DDT) [30, 31]; hexachlorobenzene [32]; and polychlorinated biphenyls $[33,34]$. There is some indication that different polychlorinated biphenyl congeners may have different associations, and that sex and height may be confounders [35]. Animal studies have demonstrated that environmental chemicals, especially those with endocrine-disrupting activity, act prenatally on adipocyte precursors to increase the number of adipocytes; to modify the way adipocytes store and metabolise fat postnatally, especially in the presence of a high-fat diet; and increase the secretion of pro-inflammatory cytokines from adipocytes [28, 36, 37]. Similar data are lacking for humans.

Studies in adolescents have implicated associations between obesity and serum concentrations of perfluoroalkyl chemicals [38] and urinary BPA [39]. Associations with various phthalates [40] and metals [41] have shown either positive, negative or no relationship with obesity. In addition, at least one study has shown a relationship between increasing BPA concentrations and reduced BMI/adiposity in girls at 9 years of age [42], which suggests these relationships are quite complex.

The gastrointestinal microbiota is a key component of human homeostasis and "peripheral metabolism" (i.e. occurring in the gut) increases energy extraction from food [43]. Alterations to the gastrointestinal microbiota (dysbiosis) have been described in a variety of chronic inflammatory diseases, such as inflammatory bowel disease, obesity and asthma. These changes commonly involve a reduction in so-called probiotic species, including Lactobacillus and Bifidobacterium, as well as outgrowth of potentially pathogenic bacteria [44]. The gastrointestinal microbiota is susceptible to environmental influences, include place and mode of delivery [45], and the presence of siblings and pets in the home in early life [46]. The composition of the microbiota may protect or predispose individuals to obesity [43]. The infant bowel is sterile at birth and the microbiota is established in early postnatal life [47, 48]. The composition of the microbiota is different in breast- and formula-fed infants, and the timing of cessation of breastfeeding is an important event in establishing the microbiota [47]. Infants with more short-chain fatty

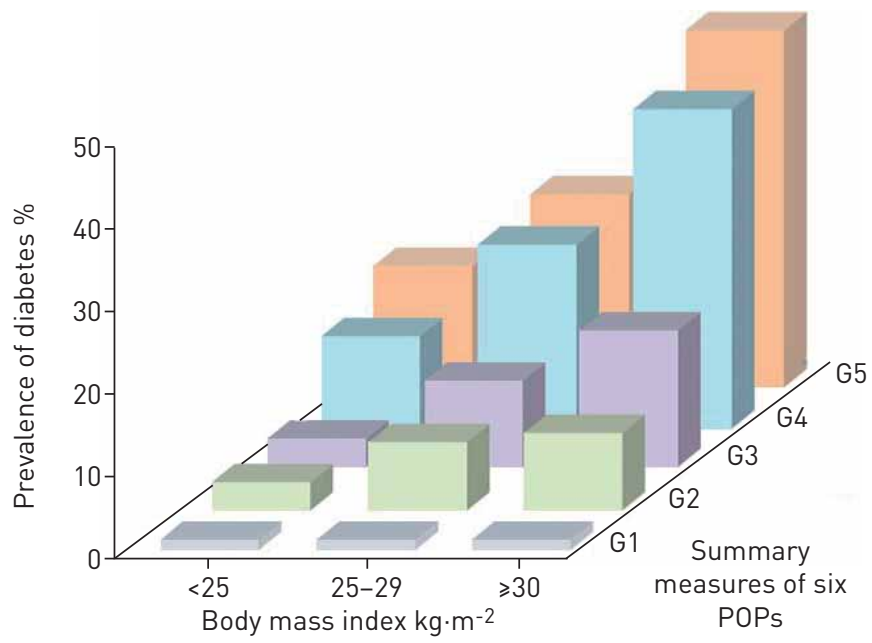

FIGURE 1 Influence of serum levels of persistent organic pollutants (POPs) on risk of diabetes. The population is divided into quintiles of serum levels of six POPs (from G1 (lowest) to G5 (highest) levels) and by body mass index. Reproduced from [22] with permission from the publisher. 


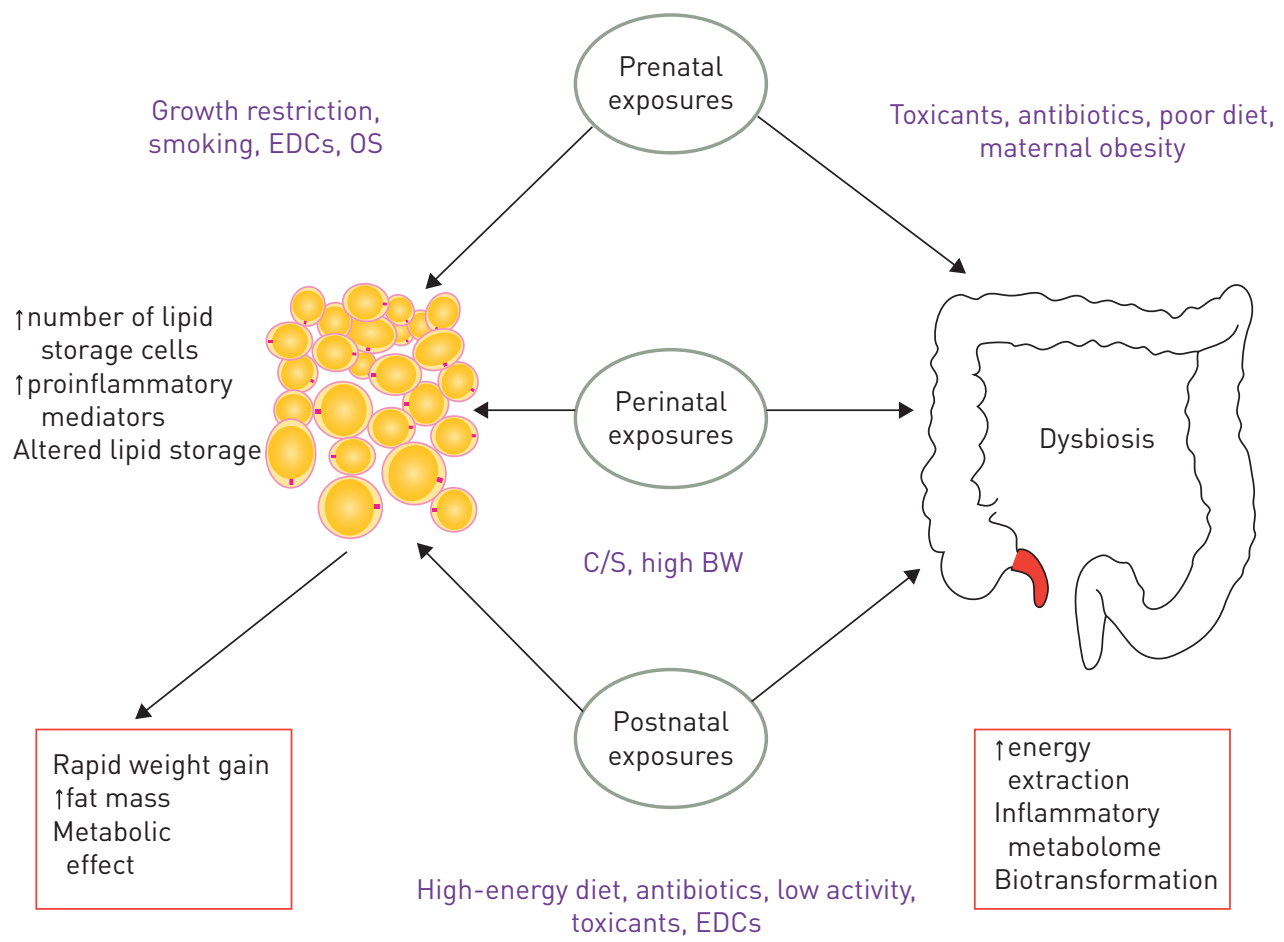

FIGURE 2 Schematic representation of the potential roles of environmental exposures in early life in increasing the risk of obesity/type II diabetes. Common exposures influencing two "target organs", adipocytes and the gastrointestinal microbiota, are shown. EDC: endocrine-disrupting chemical; OS: oxidative stress; C/S: caesarean section; BW: birth weight.

acid-producing bacteria have a more rapid increase in BMI in early life [47]. The gastrointestinal microbiota is also involved in the biotransformation of environmental toxicants [49] and may increase or decrease the toxicity of the chemical. There is little direct knowledge to determine what contribution biotransformation of such chemicals may make to human disease. Figure 2 depicts a schema linking prenatal and early-life environmental exposures with the risk of obesity/type II diabetes. The main targets of environmental exposures are adipocyte precursors and adipocytes, and the gastrointestinal microbiota. While direct evidence in humans is not available for some aspects of this schema, it does suggest an agenda for fruitful research.

Perinatal exposure to a variety of environmental toxins has been associated with low birth weight, including phthalates [50], perfluorinated compounds [51-53] and occupational exposures to pesticides [54]. Furthermore, there appear to be relationships of environmental toxins with birth at lower gestational age, and phthalates $[55,56]$ and perfluorinated compounds $[51,53]$ with preterm birth.

Reduced gestational age and preterm birth have been shown to be associated with insulin resistance, and future obesity and type II diabetes. DARROw et al. [52] also found a relationship between serum levels of perfluorinated compounds, such those found in non-stick cookware, and pregnancy-induced hypertension, which has been shown to be associated with future maternal obesity and diabetes $[57,58]$. Babies born to mothers with gestational diabetes are more likely to be born large for gestational age [59]; these babies have an increased risk of future obesity and type II diabetes. Few studies have investigated links between environmental toxicants and gestational diabetes. One study failed to show a relationship between maternal BPA exposure and gestational diabetes [60]. Exploration of the role that environmental toxins may have in the development of gestational diabetes and the role this plays on the development of fetal macrosomia would be a fruitful area for future research.

Overweight in adults is a major risk factor for development of diabetes, hypertension, heart disease and stroke [61]. There is strong evidence that obesity during childhood increases risk of type II diabetes [62], hypertension [63], ischaemic heart disease and stroke later in life [64, 65]. The Bogalusa Heart Study found that the critical factor was central obesity, even in children of "normal" weight, and that these children were at significantly elevated risk of hyperlipidaemia and elevated insulin levels [66]. Many of the same contaminants that increase the risk of obesity following early-life exposure also increase risk of diabetes, although these studies have usually been conducted in adults, for example polychlorinated biphenyls and organochlorine pesticides $[67,68]$. 
TABLE 3 Environmental links to obesity/type II diabetes

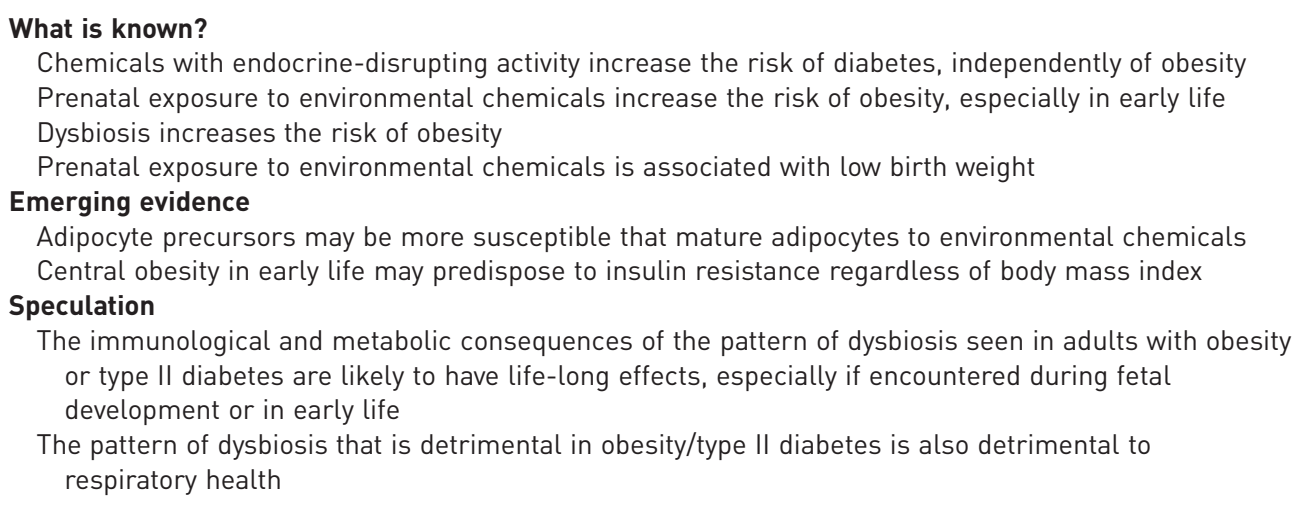

Environmental links to obesity/type II diabetes are summarised in table 3.

\section{Link to respiratory disease}

The association between asthma and obesity has been demonstrated in many cross-sectional and prospective epidemiological studies published in diverse populations [69]. The consistency of the obesityasthma link suggests that this association is not spurious. A number of early-life factors may predispose individuals to expressing both phenotypes including those discussed below. HALLSTRAND et al. [70] reported genetic analyses of monozygotic and dizygotic twin pairs, and showed that $8 \%$ of the genetic component of obesity is shared with asthma. Several linkage analyses have revealed genome regions that may harbour susceptibility genes for both asthma and obesity, including overlaps noted at positions $5 \mathrm{q}, 6 \mathrm{p}, 11 \mathrm{q}$ and $12 \mathrm{q}$ [71-73]. Polymorphisms in five genes have been associated with both asthma and obesity: ADRB2 $\left(\beta_{2}\right.$-adrenergic receptor), TNFA (tumour necrosis factor (TNF)- $\alpha$ ) [74, 75], LPA (lymphotoxin- $\alpha$ ) [76-78], $V D R$ (vitamin D receptor) [79-81] and PRKCA (protein kinase $\mathrm{C} \alpha$ ). These findings suggest that certain genetic variants may have pleiotropic effects on both obesity and asthma, and/or influence pathways that are common to both. However, further studies will be required to investigate whether specific genetic variants influence both obesity and asthma.

Rapid early-life weight gain, independent of birth weight, is associated with adult obesity [82, 83]; however, whether this contributes to the associations between asthma and obesity is not clear from the current literature. In addition, as highlighted later, fetal growth restriction may change these relationships.

A Western diet may increase the risk of obesity and of asthma. Obese children and adults have been reported to have low serum concentrations of antioxidants [84-87]. Maternal diet and the specific nutrients have not been explored in relation to childhood obesity or in the context of both asthma and obesity.

The effects of alterations in gastrointestinal tract (GIT) flora, including reduced diversity and the absence of "beneficial" organisms in infancy, can have long-term effects on allergic diseases [88]. While evidence in this field is sparse and still emerging, the microbes thought to be beneficial for allergic diseases and obesity appear to overlap. However, whether this apparent overlap in beneficial microbes indicates common mechanisms for allergic diseases and obesity is unknown. The GIT microbiome also differs in adults with and without type II diabetes, with changes in the relative proportions of various microorganisms [89] that were associated with plasma glucose levels [90]. However, direct links with respiratory disease are lacking.

The relationship between other respiratory diseases such as COPD and obesity is increasingly being recognised in the literature. The overall prevalence of obesity in a population of primary care patients with COPD in the Netherlands was reported as $18 \%$, compared with $10 \%$ in the general population, with the prevalence of obesity being highest in those with mild disease (Global Initiative for Chronic Obstructive Lung Disease (GOLD) stages 1 and 2) and lowest in those with severe disease (GOLD stage 4). When emphysema and chronic bronchitis are reported separately, a significantly increased prevalence of obesity is reported in chronic bronchitis (25\%) compared with controls (16\%), while underweight was more prevalent in patients with emphysema [91]. There are no data jointly linking early-life influences on both obesity and COPD.

Obesity plays a major role in the development of metabolic syndrome and has been identified as an important risk factor for chronic diseases such as type II diabetes. There are no studies specifically 
examining early-life influences in the inception of both asthma and type II diabetes, except via obesity. There are several variations to the definition of metabolic syndrome but most include abdominal obesity, atherogenic dyslipidaemia, hypertension and insulin resistance. An association between asthma and the metabolic syndrome has been suggested in a large cross-sectional analysis that indicated children diagnosed with asthma tend to have higher rates of insulin resistance and serum triglyceride levels [92], independent of the children's weight, sex and history of exposure to tobacco smoke [92]. Similarly, lung function was lower in nondiabetic adults with insulin resistance after controlling for BMI [93]. This suggests that those in the normal weight range may be more susceptible to developing asthma secondary to the metabolic derangements of increasing triglyceride or blood glucose levels, independently of BMI. Asthma symptoms are reported more frequently in subjects with metabolic syndrome [94]. Insulin resistance and diabetes are associated with reduced lung function [92, 95]. Associations have also been reported between COPD and the metabolic syndrome. Large population-based studies have demonstrated a higher prevalence of type II diabetes, hypertension, dyslipidaemia and resultant CVD in COPD [96, 97]. The prevalence of type II diabetes in COPD is estimated at 1.6-16\%, increasing with COPD severity [97, 98].

Maternal smoking during pregnancy and exposure to environmental tobacco smoke (ETS) are risk factors for obesity [29] and type II diabetes [99, 100] in later life. Maternal stressful events have also been associated with insulin resistance in the offspring in later life, even after accounting for birth weight and family history of diabetes [101]. A retrospective study of mothers who experienced bereavement during pregnancy had increased risk of having diabetic adult offspring [102]. Low socioeconomic status (SES) during childhood is a risk factor for adult type II diabetes even after correcting for SES in adult life and personal obesity $[103,104]$. The risk was amplified when childhood low SES was combined with adult obesity.

Various epidemiological studies describe an association between air pollution and type II diabetes. Although the findings have been inconsistent, when assessed as a whole, the majority of observations support the association [105].

\section{Cardiovascular disease}

The major traditional risks for CVD, tobacco smoking, high-fat diets, dyslipidaemia, obesity and exposure to ambient air pollution, have been well established through large-scale epidemiological studies conducted in adults. Environmental chemicals, including polyaromatic hydrocarbons, aldehydes and metals, are recognised as increasing the risk of CVD [106]. Fewer studies of environment contributions to CVD risks have focused on early-life exposures beyond the relationships with development of obesity. However, LAMERrill et al. [107] found that prenatal exposure to DDT and its metabolites was associated with an increased risk of hypertension at ages 37-47 years. A recent study that combined data from the Cardiovascular Risk in Young Finns study (Finland) with the Childhood Determinants of Adult Health Study (Tasmania, Australia) demonstrated that exposure to parental smoking during childhood or adolescence was associated with greater carotid intima-media thickness up to 25 years later [108]. The effect was greater if both parents smoked, and was independent of personal smoking in adulthood and uniform across categories of age, sex and cohort. Interest is increasing in the early-life origins of CVD, with an adverse intrauterine environment and fetal growth restriction becoming recognised as increasing the risk of atherosclerosis [109]. A number of early-life biomarkers of future CVD risk are emerging, including indicators of: increased vascular stiffness (carotid and aortic intima-media thickness, arterial distensibility and pulse wave velocity); endothelial dysfunction (flow-mediated vasodilatation, serum intercellular adhesion molecule 1 and vascular cell adhesion molecular 1); and of systemic inflammation (highly sensitive C-reactive protein), as well as indicators of dyslipidaemia and insulin resistance. Longitudinal birth cohorts are currently studying the influence of early-life environmental exposures on long-term cardiovascular health using such early-life biomarkers of the effects of exposure, with a major concentration of presumed epigenetic mechanisms [109]. We await the results of such studies with interest.

Environmental links to CVD are summarised in table 4.

\section{Link to respiratory diseases}

There is now considerable evidence of an association between respiratory disease, such as asthma and COPD, and CVD. Figure 3 shows a schematic representation of common risk factors that may link these diseases. CVD is a major contributor to morbidity and mortality in patients with COPD [110-112]. In a large cohort study of patients with COPD, the prevalence of coronary artery disease was 33.6\%, compared with $27.1 \%$ in an age- and sex-matched cohort without COPD [113]. In addition, a number of population studies have shown that airflow limitation (low forced expiratory volume in $1 \mathrm{~s}$ (FEV1)) or FEV1/forced vital capacity ratio is a predictor of cardiovascular risk [112]. In the Lung Health Study of 5887 patients with COPD patients, CVD was the leading cause of death [114]. 


\section{TABLE 4 Environmental links to cardiovascular disease}

\section{What is known?}

Traditional risk factors for cardiovascular disease in adults are well established

\section{Emerging evidence}

Adverse intrauterine environments increase life-long risks of cardiovascular disease

Biomarkers of vascular stiffness and endothelial dysfunction in early life predict future cardiovascular disease

Speculation

Environmental exposures in early life increase the risk of cardiovascular disease more than similar exposures in later life

ETS exposure in adults is associated with impaired arterial endothelial function [115], increased arterial wall thickness [116] and lipid alterations [117] that favour atherosclerosis. The same effects have been demonstrated in some $[118,119]$ but not all studies 120 in children. Passive smoke inhalation has also shown to increase the likelihood of fatal and nonfatal myocardial infarction [120]. Large prospective cohort studies looking at children and adults exposed to maternal smoking during pregnancy have reported an increased CVD risk profile including obesity [121-124], higher systolic blood pressure [125], higher atherogenic lipoproteins and triglycerides [126]. While the role of maternal smoking on the subsequent susceptibility to cardiovascular disease is recognised, the mechanism underlying this effect is not well understood and is an area of research need. There are no studies investigating the effect of in utero cigarette smoke exposure and the direct links between CVD and COPD.

The associations between low birth weight and CVD, type II diabetes, hypertension and obesity in later life are well recognised [127-129]. The associations seem to be consistent and stronger among subjects with postnatal catch-up growth. Well-designed epidemiological studies that take into account confounding factors are needed to further elucidate the associations of lung disease and low birth weight and the link with CVD.

Exposure to air pollution may be causally linked to CVD. All commonly measured ambient air pollutants are positively associated with increased hospitalisation $[130,131]$ and mortality due to CVD [132-134]. Particulate matter exposure in animal studies induced more advanced and larger coronary lesions, more extensive atherosclerosis in the aorta, and more unstable plaques [135]. Studies of the effect of particulate matter exposure in humans have shown it causes tachycardia and hypertension, and increases in blood viscosity [136], coagulation factors [137], inflammatory mediators [137] and endothelial injury/ dysfunction [138]. Collectively, these responses may result in adverse cardiovascular events by causing myocardial ischaemia [139], malignant ventricular arrhythmias [140], increased plaque vulnerability and enhanced potential for acute thrombosis triggering acute coronary syndromes. Despite the growing evidence of the deleterious effects of early-life ambient air pollution on COPD and CVD, there are no studies linking the two directly.

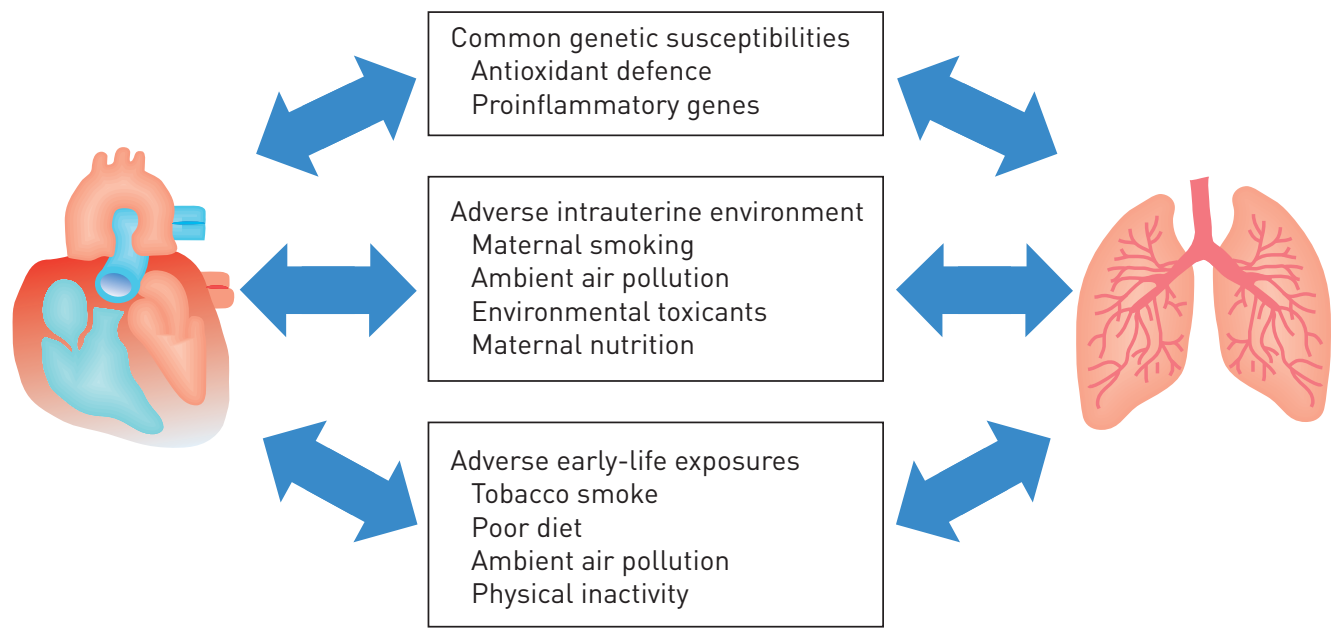

FIGURE 3 Schematic representation of the common risk factors underlying the associations between cardiovascular disease and respiratory disease. 
There may be a shared genetic susceptibility between COPD and CVD in antioxidant defence system genes. Complex polygenic interactions of the matrix metalloproteases [141-143] and polymorphisms of epoxide hydrolase $[144,145]$ have been identified as a possible genetic link between COPD and CVD. The adverse health consequences of exposure to ambient air pollution are magnified in those less able to defend against oxidative stress. Several studies have also demonstrated an association between asthma and CVD. Subjects with adult-onset asthma are at increased risk of CVD including carotid atherosclerosis, coronary heart disease or stroke [146-149].

\section{Neurocognitive disorders}

There is an increasing recognition of the major impact that mental health disorders, in the broadest use of the term, have on society. In children, neurocognitive disorders, such as autism spectrum disorder, attention deficit hyperactivity disorder, mental retardation, dyslexia and other biological disorders of the brain, are common [150], with between 400000 and 600000 of the 4 million babies born each year in the USA affected. Globally, childhood behavioural disorders contribute 5.75 million disability-adjusted life-years, a substantial proportion of the total burden of disease. They are particularly prominent in terms of nonfatal burden, accounting for $0.8 \%$ of the years lived with disability across all ages [151]. Attention deficit hyperactivity disorder is diagnosed in mid-childhood and the prevalence declines with age, being 5$10 \%$ in childhood, $2.5-4 \%$ in adolescents and $2.5 \%$ in adults [152, 153]. A recent pooled analysis suggested a global prevalence of $5.3 \%$ for attention deficit hyperactivity disorder in children and adolescents, although parental reports of symptoms consistent with attention deficit hyperactivity disorder often give higher estimates, with $7.2 \%$ of American children $4-17$ years of age reported by parents to have a current diagnosis of attention deficit hyperactivity disorder [154]. By any measure neurocognitive disorders in children and adolescents impose a huge burden on society.

Attention deficit hyperactivity disorder often co-occurs with other neurobehavioural disorders. AgUIAR et al. [152] reported that the most common comorbidities in boys are oppositional defiant disorder $(>32 \%)$ and conduct disorders (>7\%), while anxiety disorders (33\%) are more common in girls, and depression and bipolar disorders are common in adolescents. There is less certainty over whether attention deficit hyperactivity disorder is associated with decreased cognitive function and lower intelligence quotient (IQ), although several of the environmental exposures associated with attention deficit hyperactivity disorder (see later), including lead [155], polychlorinated biphenyls [155], organochlorine pesticides [155], organophosphate pesticides and tobacco smoke [156], are associated with lower IQ. A recent meta-analysis that included 137 comparisons of full-scale IQ among children with attention deficit hyperactivity disorder and controls concluded that a reduction of 9 points was seen with attention deficit hyperactivity disorder [154].

Attention deficit hyperactivity disorder is considered to be a highly heritable disorder, with pooled data from twin studies suggesting a heritability of $76 \%$ [157]. Considerable evidence suggests that neurocognitive disorders result from complex interactions of genetic, environmental and social factors [158]. The developing human brain is exquisitely sensitive to toxic chemicals [150] and early-life exposure to environmental toxicants has major impacts on neurocognitive disorders. Substantial evidence links loss of cognition (IQ), dyslexia and attention deficit hyperactivity disorder to lead, methyl mercury, organophosphate and organochlorine insecticides, polychlorinated biphenyls, arsenic, manganese, polyaromatic hydrocarbons, BPA, brominated flame retardants, and perfluorinated compounds [150]. Additional risk factors identified by longitudinal cohort studies or epidemiological studies include: low birth weight [159, 160]; head trauma [161]; low parental education level [161]; family psychosocial adversity [162-165]; family dysfunction [166]; prenatal exposure to drugs of abuse and tobacco smoke $[164,167,168]$; Western diet and no or short duration breastfeeding $[164,169]$; and maternal vitamin D insufficiency during pregnancy [170].

Environmental links to neurocognitive disorders are summarised in table 5.

\section{Link to respiratory disease}

Despite being debated for a long time, there are large epidemiological studies that have now shown an association between asthma and symptoms consistent with attention deficit hyperactivity disorder [171173], with more severe symptoms in severe asthma [171]. A schematic representation of the common risk factors for neurocognitive disorders and respiratory disease is shown in figure 4. Shared genetic susceptibilities may be involved in the link between attention deficit hyperactivity disorder and asthma. A prospective twin study indicated that $68 \%$ of the phenotypic correlation between asthma and the hyperactivity-impulsivity dimension of attention deficit hyperactivity disorder was because of genetic influences [173]. Possible shared hereditary influences could involve inflammatory pathways, including the various cytokines central to the pathogenesis of asthma. Polymorphisms of IL2 (interleukin (IL)-2), IL6 
TABLE 5 Environmental links to neurocognitive disorders

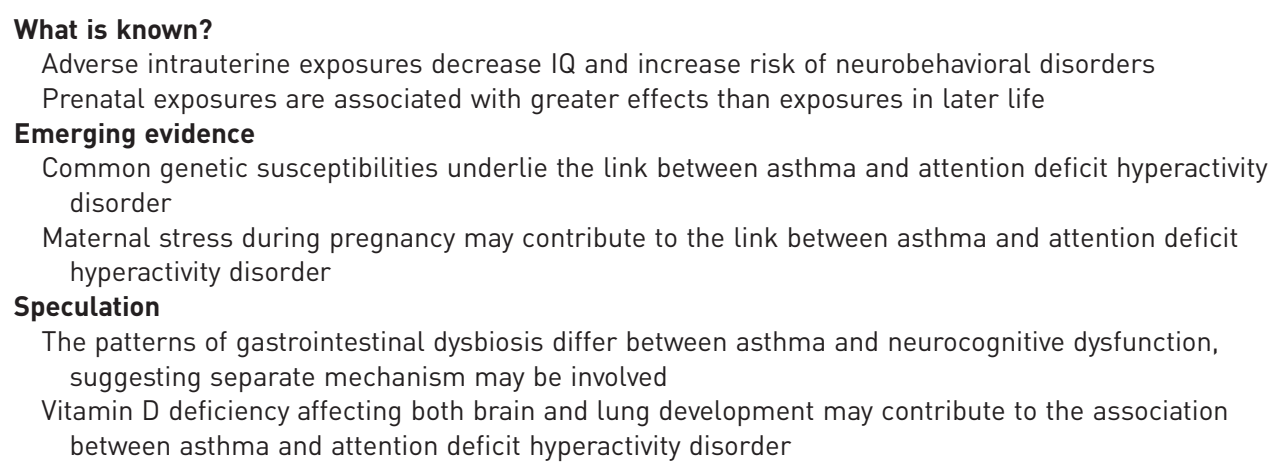

Adverse intrauterine exposures decrease $I Q$ and increase risk of neurobehavioral disorders

Prenatal exposures are associated with greater effects than exposures in later life

\section{Emerging evidence}

Common genetic susceptibilities underlie the link between asthma and attention deficit hyperactivity disorder

Maternal stress during pregnancy may contribute to the link between asthma and attention deficit hyperactivity disorder

\section{Speculation}

The patterns of gastrointestinal dysbiosis differ between asthma and neurocognitive dysfunction, suggesting separate mechanism may be involved

Vitamin $D$ deficiency affecting both brain and lung development may contribute to the association between asthma and attention deficit hyperactivity disorder

IQ: intelligence quotient.

(IL-6) and TNFA [173], and increased levels of cytokines IL-2, IL-6, TNF- $\alpha$, IL-16, IL-10 and IL-13 [175] have been shown to be associated with attention deficit hyperactivity disorder.

Pre- and postnatal tobacco smoke exposure may be a risk factor for behavioural and neurodevelopmental problems, including reduced general intellectual ability, skills in language and auditory tasks, and academic achievement, and attention deficit hyperactivity disorder [176]. Animal studies have shown that nicotine is a prenatal neuroteratogen, resulting in abnormalities of neuronal cell proliferation and differentiation, eliciting abnormalities in the number of cells and, eventually, altered synaptic activity, and could account for the neurodevelopmental deficits observed in humans [177]. Prenatal nicotine exposure alters airway growth and alters receptor expression on airway cells. Whether the mechanisms invoked are similar is not known.

Prenatal stress may provide a link between attention deficit hyperactivity disorder and asthma. Prospective studies have documented that maternal stress is positively linked to attention deficit hyperactivity disorder in the offspring [178]. This association has also been demonstrated in animal models, particularly with rodents and nonhuman primates $[179,180]$, although the mechanisms involved are not known; neither are the mechanisms underlying maternal stress and asthma, although blaming effects on the hypothalamicpituitary-adrenal axis and on cortisol secretion is popular.

The gut microbiota has been reported to differ between healthy ("neurotypical") children and those with autism spectrum disorder [181-183], with supportive mechanistic studies in animal models [184]. However, not all human studies support a role for intestinal flora in neurocognitive disorders [185]. In addition, the patterns of gastrointestinal dysbiosis implicated in neurocognitive disorders differ from that seen in obesity/type II diabetes and allergic disorders.

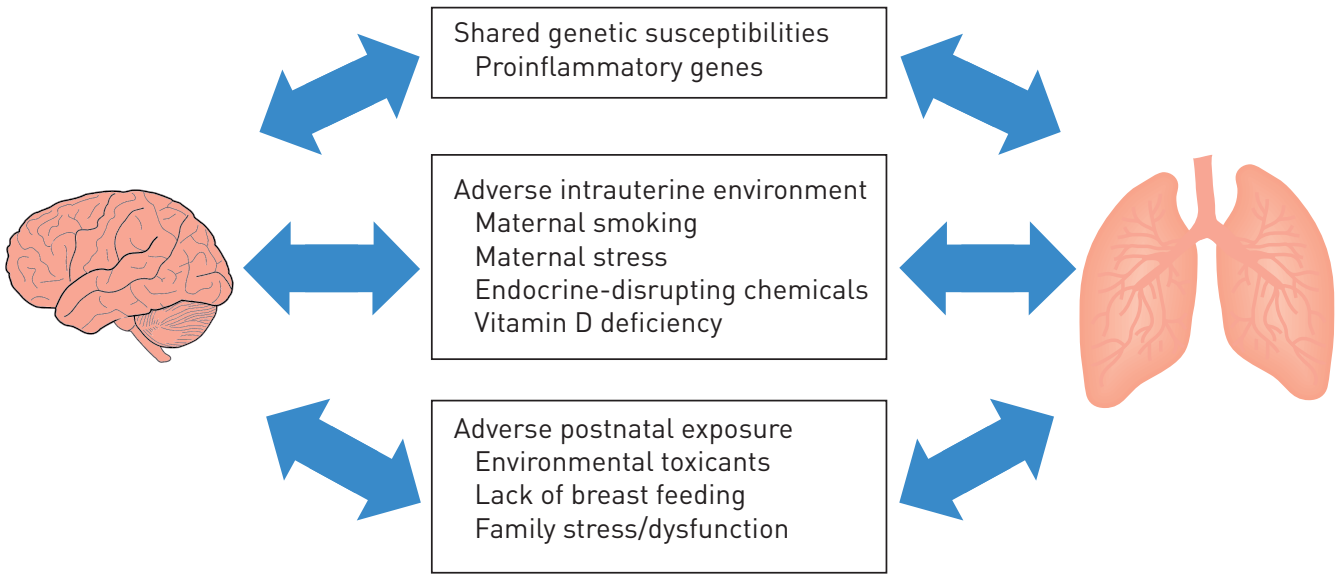

FIGURE 4 Schematic representation of the common risk factors underlying the associations between neurocognitive disorders and respiratory disease. 


\section{Conclusion}

The global burden of disease associated with both chronic respiratory and nonrespiratory diseases is substantial and increasing. As highlighted in this article, epidemiological evidence linking respiratory diseases with obesity, type II diabetes and metabolic syndrome, CVD, and neurocognitive and behavioural disorders is substantial, but few studies specifically examining direct mechanistic links exist in the human literature. Common environmental exposures in early life and shared risk factors may underlie these associations, and warrant specific study.

\section{References}

1 Lozano R, Naghavi M, Foreman K, et al. Global and regional mortality from 235 causes of death for 20 age groups in 1990 and 2010: a systematic analysis for the Global Burden of Disease Study 2010. Lancet 2012; 380: 2095-2128.

2 World Health Organization. Household Air Pollution and Health. www.who.int/mediacentre/factsheets/fs292/en/ Last updated: March 2014.

3 Vos T, Flaxman A, Naghavi M, et al. Years lived with disability (YLDs) for 1160 sequelae of 289 diseases and injuries 1990-2010: a systematic analysis for the Global Burden of Disease Study 2010. Lancet 2012; 380: 2163-2196.

$4 \quad$ Murray C, Ezzati M, Flaxman A, et al. GBD 2010: design, definitions, and metrics. Lancet 2012; 380: 2063-2066.

5 Lim S, Vos T, Flaxman AD, et al. A comparative risk assessment of burden of disease and injury attributable to 67 risk factors and risk factor clusters in 21 regions, 1990-2010: a systematic analysis for thte Global Burden of Disease Study 2010. Lancet 2012; 380: 2224-2260.

6 Sly PD, Neira M, Collman G, et al. Networking to advance progress in children's environmental health. Lancet Glob Health 2014; 2: e129-e130.

7 Balbus J, Barouki R, Birnbaum L, et al. Early-life prevention of non-communicable diseases. Lancet 2013; 381 : 3-4.

8 Gluckman P, Hansen M, Cooper C, et al. Effect of in utero and early-life conditions on adult health and disease. N Engl J Med 2008; 359: 61-73.

9 Grandjean P, Landrigan PJ. Neurobehavioural effects of developmental toxicity. Lancet Neurol 2014; 13: 330-338.

10 Lee D, Steeffes M, Sjodin A, et al. Low dose of some persistent organic pollutants predicts Type 2 diabetes: a nested case-control study. Environ Health Perspect 2010; 118: 1235-1242.

11 Newbold R. Impact of environmental endocrine disrupting chemicals on the development of obesity. Hormones 2010; 9: 206-217.

12 Slotkin T. Does early-life exposure to organophosphate insecticides lead to prediabetes and obesity? Reproductive Toxicol 2011; 31: 297-301.

13 Sly P. Environmental contributions to chronic non-communicable diseases: redefining environmental diseases. $J$ Environ Immunol Toxicol 2013; 1: 51-52.

14 Symeonides C, Ponsonby A, Vuillermin P, et al. Environmental chemical contributions to ADHD and the externalising disorders of childhood. J Environ Immunol Toxicol 2013; 1: 92-104.

15 Grant K, Carpenter D, Sly J, et al. Environmental contributions to obesity and type 2 diabetes. J Environ Immunol Toxicol 2013; 1: 80-91.

16 Puga A, Maier A, Medvedovic M. The transcriptional signature of dioxin in human hepatoma HepG2 cells. Biochem Pharmacol 2000; 60: 1129-1142.

17 Jirtle RL, Skinner M. Environmental epigenomics and disease susceptibility. Nat Rev Genet 2007; 6: 253-262.

18 Vandenberg L, Chahoud I, Heindel J, et al. Urinary, circulating and tissue biomonitoring studies indicate widespread exposure to bisphenol A. Environ Health Perspect 2010; 118: 1055-1070.

19 Carraro S, Scheltema N, Bont L, et al. Early-life origins of chronic respiratory diseases: understanding and promoting healthy ageing. Eur Respir J 2014; 44: 1682-1696.

20 Newbold R. Impact of environmental endocrine disrupting chemicals on the development of obesity. Hormones 2010; 9: 206-217.

21 Lee D, Lee I, Song K, et al. A strong dose-response relation between serum concentrations of persistent organic pollutants and diabetes. Diabetes Care 2006; 29: 1338-1644.

22 Porta M, Lee D. Review of the science linking chemical exposures to the human risk of obesity and diabetes. www.chemtrust.org.uk/wp-content/uploads/CHEM-Trust-Obesity-Diabetes-Full-Report.pdf Date last accessed: August 16, 2014. Date last updated: January 2012.

23 Alonso-Magdalena P, Ropero A, Soriano S, et al. Bisphenol-A: a new diabetogenic factor? Hormones 2010; 9 : $118-126$.

24 Makaji E, Raha S, Wade M, et al. Effect of environmental contaminants on Beta cell function. Int J Toxicol 2011; 30: $410-418$

25 Lang I, Galloway T, Scarlett A, et al. Association of urinary bisphenol A concentration with medical disorders and laboratory abnormalities in adults. J Am Med Assoc 2008; 300: 1303-1310.

26 Alonso-Magdalena P, Vieira E, Soriano S, et al. Bisphenol A exposure during pregnancy disrupts glucose homeostasis in mothers and adult male offspring. Environ Health Perspect 2010; 118: 1243-1250.

27 Ryan K, Haller A, Sorrell J, et al. Perinatal exposure to bisphenol-A and the development of metabolic syndrome in CD-1 mice. Endocrinology 2010; 151: 2603-2612.

28 Wei J, Lin Y, Li Y, et al. Perinatal exposure to bisphenol A at reference dose predisposes offspring to metabolic syndrome in adult rats on a high-fat diet. Endocrinology 2011; 152: 3049-3061.

29 Cupul-Uicab L, Skjaerven R, Huan K, et al. In utero exposure to maternal tobacco smoke and subsequent obesity, hypertension, and gestational diabetes among women in the MoBa cohort. Environ Health Perspect 2012; 120: 355-360.

30 Karmaus W, Osuch J, Eneli I, et al. Maternal levels of dichlorodiphenyl-dichloroethylene (DDE) may increase weight and body mass index in adult female offspring. Occup Environ Med 2009; 66: 143-149. 
2008; 358: 1991-2002. 27-41. 11: 307-313. 2013; 9: 15. 421-428.

Mendez M, Garcia-Esteban R, Guxens M, et al. Prenatal organochlorine compound exposure, rapid weight gain, and overweight in infancy. Environ Health Perspect 2011; 119: 272-278.

Smink A, Ribas-Fito N, Garcia R, et al. Exposure to hexachlorobenzene during pregnancy increases the risk of overweight in children aged 6 years. Acta Paediatrica 2008; 97: 1465-1469.

Valvi D, Mendez M, Martinez D, et al. Prenatal concentrations of poly chlorinated biphenyls, DDE, and DDT and overweight in children: a prospective birth cohort study. Eviron Health Perspect 2012; 120: 451-457.

Verhulst S, Nelen V, Den Hond E, et al. Intrauterine exposure to environmental pollutants and body mass index during the first 3 years of life. Environ Health Perspect 2009; 117: 122-126.

Dhooge W, Den Hond E, Koppen G, et al. Internal exposure to pollutants and body size in Flemish adolescents and adults: associations and dose-response relationships. Environ Int 2010; 36: 330-337.

Kim M, Pelloux V, Guyot E, et al. Inflammatory pathway genes belong to major targets of persistent organic pollutants in adipose cells. Environ Health Perspect 2012; 120: 205-214.

Shug T, Janesick A, Blumberg B, et al. Endocrine disrupting chemicals and disease susceptibility. J Steroid Biochem Mol Biol 2011; 127: 204-215.

Lin C, Chen P, Lin Y, et al. Association among serum perfluoroalkyl chemicals, glucose homeostasis, and metabolic syndrome in adolescents and adults. Diabetes Care 2009; 32: 702-707.

Trasande L, Attina T, Blustein J. Association between urinary bisphenol A concentration and obesity prevalence in children and adolescents. J Am Med Assoc 2012; 308: 1113-1121.

Hatch E, Nelson J, Qureshi M, et al. Association of urinary phthalate metabolic concentrations with body mass index and waist circumference: a cross-sectional study of NHANES data, 1999-2002. Eviron Health 2008; 7:

Padilla M, Elobeid M, Ruden D, et al. An examination of the association of selected toxic metals with total and central obesity indices: NHANES 99-02. Int J Environ Res Public Health 2010; 7: 3332-3347.

Harley KG, Aguilar Schall R, Chevrier J, et al. Prenatal and postnatal bisphenol A exposure and body mass index in childhood in the CHAMACOS cohort. Environ Health Perspect 2013; 121;514-20: 20e1-6.

Tsai F, Coyle WJ. The microbiome and obesity: is obesity linked to our gut flora? Curr Gastroenterol Rep 2009,

Gollwitzer ES, Marsland BJ. Microbiota abnormalities in inflammatory airway diseases: potential for therapy. Pharmacol Therapeut 2014; 141: 32-39.

van Nimwegen FA, Penders J, Stobberingh EE, et al. Mode and place of delivery, gastrointestinal microbiota, and their influence on asthma and atopy. J Allergy Clin Immun 2011; 128: 948-U371.

Azad MB, Konya $\mathrm{T}$, Maughan $\mathrm{H}$, et al. Infant gut microbiota and the hygiene hypothesis of allergic disease: impact of household pets and siblings on microbiota composition and diversity. Allergy Asthma Clin Immunol

Bergström A, Skov TH, Bahl MI, et al. Establishment of intestinal microbiota during early life: a longitudinal, explorative study of a large cohort of Danish infants. Appl Environ Microbiol 2014; 80: 2889-2900.

Pediatr Gastr Nutr 2009; 48: 249-256.

Snedeker S, Hay A. Do interactions between gut ecology and environmental chemicals contribute to obesity and diabetes? Environ Health Perspect 2012; 120: 332-339.

Philippat C, Mortamais M, Chevrier C, et al. Exposure to phthalates and phenols during pregnancy and offspring size at birth. Environ Health Perspect 2012; 120: 464-470.

Chen MH, Ha EH, Wen TW, et al. Perfluorinated compounds in umbilical cord blood and adverse birth outcomes. PLoS One 2012; 7: e42474.

Darrow LA, Stein CR, Steenland K. Serum perfluorooctanoic acid and perfluorooctane sulfonate concentrations in relation to birth outcomes in the Mid-Ohio Valley, 2005-2010. Environ Health Perspect 2013; 121: 1207-1213.

Whitworth KW, Haug LS, Baird DD, et al. Perfluorinated compounds in relation to birth weight in the Norwegian Mother and Child Cohort Study. Am J Epidemiol 2012; 175: 1209-1216.

Snijder CA, Roeleveld N, te Velde E, et al. Occupational exposure to chemicals and fetal growth: the Generation R Study. Hum Reprod 2012; 27: 910-920.

Huang Y, Li J, Garcia JM, et al. Phthalate levels in cord blood are associated with preterm delivery and fetal growth parameters in Chinese women. PLoS One 2014; 9: e87430.

Meeker JD, $\mathrm{Hu} \mathrm{H}$, Cantonwine $\mathrm{DE}$, et al. Urinary phthalate metabolites in relation to preterm birth in Mexico city. Environ Health Perspect 2009; 117: 1587-1592.

Callaway LK, Lawlor DA, O'Callaghan M, et al. Diabetes mellitus in the 21 years after a pregnancy that was complicated by hypertension: findings from a prospective cohort study. Am J Obstet Gynecol 2007; 197: 492.e1-7. Callaway LK, McIntyre HD, O'Callaghan M, et al. The association of hypertensive disorders of pregnancy with weight gain over the subsequent 21 years: findings from a prospective cohort study. Am J Epidemiol 2007; 166:

Robledo C, Peck JD, Stoner JA, et al. Is bisphenol-A exposure during pregnancy associated with blood glucose levels or diagnosis of gestational diabetes? J Toxicol Environ Health A 2013; 76: 865-873.

Field A, Coakley E, Must A, et al. Impact of overweight on the risk of developing common chronic diseases during a 10-year period. Arch Intern Med 2001; 161: 1581-1586.

Nguyen $\mathrm{Q}$, Srinivasan $\mathrm{S}$, Xu J, et al. Changes in risk variables of metabolic syndrome since childhood in pre-diabetic and type 2 diabetics subjects. Diabetes Care 2008; 31: 2044-2049.

Zhang Y, Wang S. The relationship of body mass index distribution to relatively high blood pressure among children and adolescents in Shandong, China. Ann Human Bio 2011; 38: 630-634. premature mortality in adulthood: systematic review. Int J Obesity 2011; 35: 891-898.

Williams D, Going S, Lohman T, et al. Body fatness and risk for elevated blood pressure, total cholesterol, and serum lipoprotein ratios in children and adolescents. Am J Public Health 1992; 82: 358-363. 

obesity and related cardiometabolic risk profile among normal weight and overweight/obese children: the Bogalusa heart study. BMC Pediatr 2010:10: 73.

67 Codru N, Schymura M, Negoita S, et al. Diabetes in relation to serum levels of polychlorinated biphenyls and chlorinated pesticides in adult Native Americans. Environ Health Perspect 2007; 115: 1442-1447.

68 Lee D, Lee I, Jin S, et al. Association between serum concentrations of persistent organic pollutants and insulin resistance among nondiabetic adults: results from the National Health and Nutrition Examination Survey 19992002. Diabetes Care 2007; 30: 622-628.

69 Fors E. The epidemiology of obesity and asthma. J Allergy Clin Immunol 2005; 115: 897-909.

70 Hallstrand T, Fischer M, Wurfel M, et al. Genetic pleiotropy between asthma and obesity in a community-based sample of twins. J Allergy Clin Immunol 2005; 116: 1235-1241.

71 Howard T, Meyers D, Bleecker E. Mapping susceptibility genes for asthma and allergy. J Allergy Clin Immunol 2000; 105: S477-S481.

72 Tantisira K, Weiss S. Complex interactions in complex traits: obestiy and asthma. Thorax 2001; 56: Suppl. 2, ii64-ii73.

73 Yang W, Kelly T, He J. Genetic epidemiology of obesity. Epidemiol Rev 2007; 29: 49-61.

74 Aoki T, Hirota T, Tamari M, et al. An association between asthma and TNF-308G/A polymorphism: meta-analysis. J Hum Genet 2006; 51: 677-685.

75 Sookoian S, Gonxalex C, Priola C. Meta-analysis on the G-308A tumour necrosis factor alpha gene variant and phenotypes associated with the metabolic syndrome. Obes Res 2005; 13: 2122-2131.

76 Hamid Y, Urhammer S, Glummer C, et al. The common T60N polymorphism of the lymphotoxin-alpha gene is associated with type 2 diabetes and other phenotypes of the metabolic syndrome. Diabetologia 2005; 48: 445-451.

77 Randolph A, Lange C, Silverman E, et al. Extended haplotype in the tumor necrosis factor gene cluster is associated with asthma and asthma-related phenotypes. Am J Respir Crit Care Med 2005; 172: 687-692.

78 Want T, Chen W, Want T, et al. Gene-gene synergistic effect on atopic asthma: tumour necrosis factor- $\alpha-308$ and lyphotoxin- $\alpha-N c o I$ in Taiwan's children. Clin Exp Allergy 2004; 34: 184-188.

79 Poon A, Laprise C, Lemire M, et al. Association of vitamin D receptor genetic variants with susceptibility to asthma and atopy. Am J Respir Crit Care Med 2004; 170: 967-973.

80 Raby B, Lazarus R, Silverman E, et al. Association of vitamin D receptor gene polymorphisms with childhood and adult asthma. Am J Respir Crit Care Med 2004; 170: 1057-1065.

81 Wjst M, Altmuller J, Faus-Kessler T, et al. Asthma families show transmission disequilibrium of gene variants in the vitamin D metabolism and signalling pathway. Respir Res 2006; 7: 60.

82 McCarthy A, Hughes R, Tilling K, et al. Birth weight; postnatal, infant and childhood growth; and obesity in young adulthood: evidence from the Barry Caerphilly Growth Study. Am J Clin Nutr 2007; 86: 907-913.

83 Sachdev H, Fall C, Osmond C, et al. Anthropometric indicators of body composition in young adults: relation to size at birth and serial measurements of body mass index in the New Delhi birth cohort. Am J Clin Nutr 2005; 82: 456-466.

84 Galan P, Viteri F, Bertrais S, et al. Serum concentrations of beta-carotene, vitamin C and E, zinc and selenium are influenced by sex, age, diet, smoking status, alcohol consumption and corpulence in a general French adult population. Eur J Clin Nutr 2005; 59: 1181-1190.

85 Kimmons J, Blanck H, Tohill B, et al. Associations between body mass index and the prevalence of low micronutrient levels among US adults. Med Gen Med 2006; 8: 59.

86 Parikh S, Edelman M, Uwaifo G, et al. The relationship between obesity and serum 1,25-dihydroxy vitamin D concentrations in healthy adults. J Clin Endocrinol Metab 2004; 89: 1196-1199.

87 Snijder M, van Dam R, Visser M, et al. Adiposity in relation to vitamin D status and parathyroid hormone levels: a population-based study in older men and women. J Clin Endocrinol Metab 2005; 90: 4119-4123.

88 Bisgaard H, Li N, Bonnelykke K, et al. Reduced diversity of the intestinal microbiota during infancy is associated with increased risk of allergic disease at school age. J Allergy Clin Immun 2011; 128: 646-652.

89 Qin J, Li Y, Cai Z, et al. A metagenome-wide association study of gut microbiota in type 2 diabetes. Nature 2012; 490: 55-60.

90 Larsen N, Vogensen F, van den Berg F, et al. Gut microbiota in humn adults with type 2 diabetes differs from non-diabetic adults. PLoS One 2010; 5: e9085.

91 Guerra S, Sherrill D, Bobadilla A, et al. The relation of body mass index to asthma, chronic bronchitis, and emphysema. Chest 2002; 122: 1256-1263.

92 Engström G, Hedblad B, Nilsson P, et al. Lung function, insulin resistance and incidence of cardiovascular disease: a longitudinal cohort study. J Intern Med 2003; 253: 574-581.

93 Lazarus R, Sparrow D, Weiss S. Impaired ventilatory function and elevated insulin levels in nondiabetic males: the Normative Aging Study. Eur Respir J 1998; 12: 635-640.

94 Lee E, In K, Ha E, et al. Asthma-like symptoms are increased in the metabolic syndrome. J Asthma 2009; 46: $339-342$.

95 McKeever T, Weston P, Hubbard R, et al. Lung function and glucose metabolism: an analysis of data from the Third National Health and Nutrition Examination Survey. Am J Epidemiol 2005; 161: 546-556.

96 de Lucas-Ramos P, Izquierdo-Alonso J, Rodríguez-González Moro J, et al. Cardiovascular risk factors in chronic obstructive pulmonary disease: results of the ARCE study. Arch Bronconeumol 2008; 44: 233-238.

97 Mannino D, Thorn D, Swensen A, et al. Prevalence and outcomes of diabetes, hypertension and cardiovascular disease in COPD. Eur Respir J 2008; 32: 962-969.

98 Barnes P, Celli B. Systemic manifestations and comorbidities of COPD. Eur Respir J 2009; 33: 1165-1185.

99 Bruin J, Kellenberger L, Gerstein H, et al. Fetal and neonatal nicotine exposure and postnatal glucose homeostasis: identifying critical windows of exposure. J Endocrinol 2007; 194: 171-178.

100 Montgomery S, Ekbom A. Smoking during pregnancy and diabetes mellitus in a British longitudinal birth cohort. BMJ 2002; 324: 26-27.

101 Entringer S, Wüst S, Kumsta R, et al. Prenatal psychosocial stress exposure is associated with insulin resistance in young adults. Am J Obstet Gynecol 2008; 199: e1-7. 
Li J, Olsen J, Vestergaard M, et al. Prenatal exposure to bereavement and type-2 diabetes: a Danish longitudinal population based study. PLoS One 2012:7e43508.

Maty S, Lynch J, Raghunathan T, et al. Childhood socioeconomic position, gender, adult body mass index, and incidence of type 2 diabetes mellitus over 34 years in the Alameda County Study. Am J Public Health 2008; 98: 1486-1494.

Tamayo T, Christian H, Rathmann W. Impact of early psychosocial factors (childhood socioeconomic factors and adversities) on future risk of type 2 diabetes, metabolic disturbances and obesity: a systematic review. BMC Public Health 2010; 10: 525.

Rajagopalan S, Brook R. Air pollution and type 2 diabetes: mechanistic insights. Diabetes 2012; 61: 3037-3045. O'Toole T, Conklin D, Bhatnagan A. Environmental risks for heart disease. Rev Environ Health 2008; 23: 167-202.

La Merrill M, Cirillo P, Terry M, et al. Prenatal exposure to the pesticide DDT and hypertension diagnosed in women before age 50: a longitudinal birth cohort study. Environ Health Perspect 2013; 121: 594-599.

Gall S, Huynh Q, Magnussen C, et al. Exposure to parental smoking in childhood or adolescence is associated with increased carotid intima-media thickness in young adults: evidence from the Cardiovascular Risk in Young Finns and the Childhood Determinants of Adult Health Study. Eur Heart J 2014; 35: 2484-2491.

Sun C, Burgner D, Ponsonby A, et al. Effects of early-life environmental and epigenetics on cardiovascular disease risk in children: highlighting the role of twin studies. Pediatr Res 2013; 73: 523-530.

Curkendall SM, DeLuise C, Jones JK, et al. Cardiovascular disease in patients with chronic obstructive pulmonary disease, Saskatchewan Canada cardiovascular disease in COPD patients. Ann Epidemiol 2006; 16: 63-70.

McGarvey LP, John M, Anderson JA, et al. Ascertainment of cause-specific mortality in COPD: operations of the TORCH Clinical Endpoint Committee. Thorax 2007; 62: 411-415.

mortality. Proc Am Thorac Soc 2005; 2: 8-11.

Macchia A, Monte S, Romero M, et al. The prognostic influence of chronic obstructive pulmonary disease in patients hospitalised for chronic heart failure. Eur J Heart Fail 2007; 9: 942-948.

Respir Crit Care Med 2002; 166: 333-339.

Celermajer DS, Adams MR, Clarkson P, et al. Passive smoking and impaired endothelium-dependent arterial dilatation in healthy young adults. N Engl J Med 1996; 334: 150-154.

Howard G, Burke GL, Szklo M, et al. Active and passive smoking are associated with increased carotid wall thickness. The Atherosclerosis Risk in Communities Study. Arch Intern Med 1994; 154: 1277-1282.

Valkonen M, Kuusi T. Passive smoking induces atherogenic changes in low-density lipoprotein. Circulation 1998; 97: 2012-2016.

Kallio K, Jokinen E, Hamalainen M, et al. Decreased aortic elasticity in healthy 11-year-old children exposed to tobacco smoke. Pediatrics 2009; 123: e267-73.

Kallio K, Jokinen E, Raitakari OT, et al. Tobacco smoke exposure is associated with attenuated endothelial function in 11-year-old healthy children. Circulation 2007; 115: 3205-3212.

Leeson CP, Whincup PH, Cook DG, et al. Flow-mediated dilation in 9- to 11-year-old children: the influence of intrauterine and childhood factors. Circulation 1997; 96: 2233-2238.

Al Mamun A, Lawlor D, Alati R, et al. Does maternal smoking during pregnancy have a direct effect on future offspring obesity? Evidence from a prospective birth cohort study. Am J Epidemiol 2006; 164: 317-325.

Oken E, Levitan E, Gillman M. Maternal smoking during pregnancy and child overweight: systematic review and meta-analysis. Int J Obes 2008; 32: 201-210.

Power C, Atherton K, Thomas C. Maternal smoking in pregnancy, adult adiposity and other risk factors for cardiovascular disease. Atherosclerosis 2010; 211: 643-648. Eur J Pediatr 2002; 161: 445-448.

Morley R, Leeson Payne C, Lister G, et al. Maternal smoking and blood pressure in 7.5 to 8 year old offspring. Arch Dis Child 1995; 72: 120-124.

Jaddoe V, de Ridder M, van den Elzen A, et al. Maternal smoking in pregnancy is associated with cholesterol development in the offspring: a 27-years follow-up study. Atherosclerosis 2008; 196: 42-48.

Bruce K, Hanson M. The developmental origins, mechanisms, and implications of metabolic syndrome. J Nutr 2010; 140: 648-652.

Fernandez-Twinn D, Ozanne S. Mechanisms by which poor early growth programs type-2 diabetes, obesity and the metabolic syndrome. Physiol Behav 2006; 88: 234-243.

Huxley R, Owen C, Whincup P, et al. Birth weight and subsequent cholesterol levels: exploration of the "fetal origins" hypothesis. J Am Med Assoc 2004; 292: 2755-2764.

Peters A, Liu E, Verrier RL, et al. Air pollution and incidence of cardiac arrhythmia. Epidemiol 2000; 11: 11-17. Poloniecki JD, Atkinson RW, de Leon AP, et al. Daily time series for cardiovascular hospital admissions and previous day's air pollution in London, UK. Occup Environ Med 1997; 54: 535-540.

Dominici F, McDermott A, Daniels M, et al. Mortality Among Residents of 90 Cities. Boston, Health Effects Institute, 2003.

Pope CA, Burnett RT, Thurston GD, et al. Cardiovascular mortality and long-term exposure to particulate air pollution - epidemiological evidence of general pathophysiological pathways of disease. Circulation 2004; 109: 71-77.

Samet JM, Dominici F, Curriero FC, et al. Fine particulate air pollution and mortality in 20 US Cities, 19871994. N Engl J Med 2000; 343: 1742-1749. Cardiol 2002; 39: 935-942.

Peters A, Döring A, Wichmann $\mathrm{H}$, et al. Increased plasma viscosity during an air pollution episode: a link to mortality? Lancet 1997; 49: 1582-1587.

Seaton A, Soutar A, Crawford V, et al. Particulate air pollution and the blood. Thorax 1999; 54: 1027-1032. 
Donaldson K, Stone V, Seaton A, et al. Ambient particle inhalation and the cardiovascular system: potential mechanisms. Environ Health Perspect 2001; 109: 523-527.

Pekkanen J, Peters A, Hoek G, et al. Particulate air pollution and risk of ST-segment depression during repeated submaximal exercise tests among subjects with coronary heart disease - the exposure and risk assessment for fine and ultrafine particles in ambient air (ULTRA) study. Circulation 2002; 106: 933-938.

Peters A, Dockery DW, Muller JE, et al. Increased particulate air pollution and the triggering of myocardial infarction. Circulation 2001; 103: 2810-2815.

Abilleira S, Bevan S, Markus H. The role of genetic variants of matrix metalloproteinases in coronary and carotid atherosclerosis. J Med Genet 2006; 43: 897-901.

Churg A, Zhou S, Wright J. Matrix metalloproteinases in COPD. Eur Respir J 2012; 39: 197-209.

Wang J, Xu D, Wu X, et al. Polymorphisms of matrix metalloproteinases in myocardial infarction: a meta-analysis. Heart 2011; 97: 1542-1546.

Singh N, Sinha N, Kumar S, et al. Glutathione S-transferase gene polymorphism as a susceptibility factor for acute myocardial infarction and smoking in the North Indian population. Cardiol 2011; 118: 16-21.

Wang Y, Ulu A, Zhang L, et al. Soluble epoxide hydrolase in atherosclerosis. Curr Atheroscler Rep 2010; 12: $174-183$

Iribarren C, Tolstykh IV, Miller MK, et al. Adult asthma and risk of coronary heart disease, cerebrovascular disease, and heart failure: a prospective study of 2 matched cohorts. Am J Epidemiol 2012; 176: 1014-1024.

Onufrak S, Abramson J, Vaccarino V. Adult-onset asthma is associated with increased carotid atherosclerosis among women in the atherosclerosis risk in communities (ARIC) study. Atherosclerosis 2007; 195: $129-137$.

Schanen JG, Iribarren C, Shahar E, et al. Asthma and incident cardiovascular disease: the Atherosclerosis Risk in Communities Study. Thorax 2005; 60: 633-638.

Zureik M, Kony S, Neukirch C, et al. Bronchial hyperresponsiveness to methacholine is associated with increased common carotid intima-media thickness in men. Arterioscl Throm Vas 2004; 24: 1098-1103.

Landrigan P, Lambertini L, Birnbaum L. A research strategy to discover the environmental causes of autism and neurodevelopmental disabilities. Environ Health Perspect 2012; 120: A258-A260.

Murray CJ, Vos T, Lozano R, et al. Disability-adjusted life years (DALYs) for 291 diseases and injuries in 21 regions, 1990-2010: a systematic analysis for the Global Burden of Disease Study 2010. Lancet 2013; 380: 2197-2223.

Aguiar A, Eubig PA, Schantz SL. Attention deficit/hyperactivity disorder: a focused overview for children's environmental health researchers. Environ Health Perspect 2010; 118: 1646-1653.

Polanczyk G, Silva de Lima M, Horta B, et al. The worldwide prevalence of ADHD: a systematic review and metaregression analysis. Am J Psychiatry 2007; 164: 942-948.

Bellinger D. A strategy for comparing the contributions of environmental chemicals and other risk factors to neurodevelopment of children. Environ Health Perspect 2012; 120: 501-507.

Eubig P, Aguiar A, Schantz S. Lead and PCBs as risk factors for attention deficit/hyperactivity disorder. Environ Health Perspect 2010; 118: 1654-1667.

Yolton K, Dietrich K, Auinger P, et al. Exposure to environmental tobacco smoke and cognitive abilities among U.S. children and adolescents. Environ Health Perspect 2005; 113: 98-103.

Smith A, Mick E, Faraone S. Advances in genetic studies of attention-deficit/hyperactivity disorder. Curr Psychiatry Rep 2009; 11: 143-148.

Pennington B, McGrath L, Rosenberg J, et al. Gene $\times$ environment interactions in reading disability and attention-deficit/hyperactivity disorder. Dev Psychol 2009; 45: 77-89.

Lawlor D, Majman J, Batty G, et al. Early life predictors of childhood intelligence: findings from the Mater-University Study of Pregnancy and its outcomes. Paediatr Perinat Epidemiol 2006; 20: 148-162.

Sorensen H, Sabroe S, Olsen J, et al. Birth weight and cognitive function in young adult life: historical cohort study. BMJ 1997; 315: 410-413.

StSauver J, Barbaresi W, Katusic S, et al Early life risk factors for attention-deficit/hyperactivity disorder: a population-based cohort study. Mayo Clin Proc 2004; 79: 1124-1131.

Biederman J. Family-environment risk factors for attention-deficit hyperactivity disorder. A test of Rutter's indicators of adversity. Arch Gen Psychiatr 1995; 52: 464-470.

Robinson M, Mattes E, Oddy W, et al. Prenatal stress and risk of behavioral morbidity from age 2 to 14 years: the influence of the number, type and timing of stressful life events. Dev Psychpathol 2011; 23: 507-520.

Robinson M, Oddy W, Li J, et al. Pre- and postnatal influences on preschool mental health: a large-scale cohort study. Child Psychol Psychiatr 2008; 49: 1118-1128.

Ronald A, Pennell C, Whitehouse A. Prenatal maternal stress associated with ADHD and autistic traits in early childhood. Front Psychol 2011; 1: 1-8.

Robinson M, Oddy W, McLean N, et al. Low-moderate prenatal alcohol exposure and risk to child behavioural development: a prospective cohort study. BJOG 2010; 117: 1139-1152.

Kalbrenner A, Braun J, Durkin M, et al. Maternal smoking during pregnancy and the prevalence of autism spectrum disorders, using data from the autism and developmental disabilities monitoring network. Environ Health Perspect 2012; 120: 1042-1048.

Mick E, Biederman J, Faraone S, et al. Case-control study of attention deficit hyperactivity disorder and maternal smoking, alcohol use and drug use during pregnancy. J Am Acad Child Adol Psychiatr 2002; 41: 378-385.

Oddy W, Kendall G, Li J, et al. The long-term effects of breastfeeding on child and adolescent mental health: a pregnancy cohort study followed for 14 years. J Pediatr 2010; 156: 568-574.

Whitehouse A, Holt B, Serralha M, et al. Maternal serum vitamin D levels during pregnancy and offspring neurocognitive development. Pediatr 2012; 129: 485-493.

1 Blackman J, Gurka M. Developmental and behavioral comorbidities of asthma in children. J Dev Behav Pediatr 2007; 28: 92-99.

Chen M, Su T, Chen Y, et al. Asthma and attention-deficit/hyperactivity disorder: a nationwide population-based prospective cohort study. J Child Psychol Psychiatr 2013; 54: 1208-1214.

3 Mogensen N, Larsson H, Lundholm C, et al. Association between childhood asthma and ADHD symptoms in adolescence-a prospective population-based twin study. Allergy 2011; 66: 1224-1230. 
Drtilkova I, Sery O, Theiner P, et al. Clinical and molecular-genetic markers of ADHD in children. Neuro Endocrinol Lett 2008; 29: 320-327.

175 Oades RD, Dauvermann MR, Schimmelmann BG, et al. Attention-deficit hyperactivity disorder (ADHD) and glial integrity: S100B, cytokines and kynurenine metabolism - effects of medication. Behav Brain Funct 2010; 6: 29.

176 Eskenazi B, Castorina R. Association of prenatal maternal or postnatal child environmental tobacco smoke exposure and neurodevelopmental and behavioral problems in children. Environ Health Perspect 1999; 107: 991-1000.

177 Thomas JD, Garrison ME, Slawecki CJ, et al. Nicotine exposure during the neonatal brain growth spurt produces hyperactivity in preweanling rats. Neurotoxicol Teratol 2000; 22: 695-701.

178 Ronald A, Pennell CE, Whitehouse AJ. Prenatal maternal stress associated with ADHD and autistic traits in early childhood. Front Psychol 2010; 1: 223.

179 Beydoun H, Saftlas AF. Physical and mental health outcomes of prenatal maternal stress in human and animal studies: a review of recent evidence. Paediatr Perinat Epidemiol 2008; 22: 438-466.

180 Boksa P. Effects of prenatal infection on brain development and behavior: a review of findings from animal models. Brain Behav Immun 2010; 24: 881-897.

181 Adams J, Jahansen L, Powell L, et al. Gastrointestinal flora and gastrointestinal status in children with autism comparisons to typical children and correlation with autism severity. Gastroenterol 2011; 11: 22.

182 Kang DW, Park J, Ihran Z, et al. Reduced incidence of Prevotella and other fermenters in intestinal microflora of autistic children. PLoS One 2013; 8: e68322.

183 Parracho H, Bingham M, Gibson G, et al. Differences between the gut microflora of children with autistic spectrum disorders and that of healthy children. J Med Microbiol 2005; 54: 987-991.

184 Hsiao E, McBride S, Hsien S, et al. Micobiota modulate behavioural and physiological abnormalities associated with neurodevelopmental disorders. Cell 2013; 155: 1451-1463.

185 Gondalia S, Palombo E, Knowles S, et al. Molecular characterization of gastrointestinal microbiota of children with autism (with and without gastrointestinal dysfunction) and their neurotypical siblings. Autism Res 2012; 5: 419-427. 